\section{(2) OPEN ACCESS}

\title{
National movement patterns during the COVID-19 pandemic in New Zealand: the unexplored role of neighbourhood deprivation
}

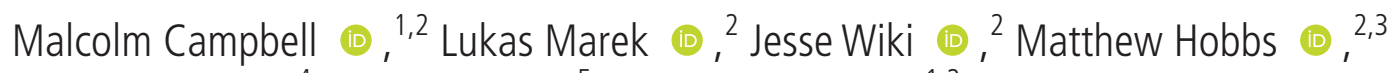 \\ Clive E Sabel (10, ${ }^{4}$ John McCarthy, ${ }^{5}$ Simon Kingham (1) ${ }^{1,2}$
}

\begin{abstract}
- Additional material is published online only. To view, please visit the journal online (http://dx.doi.org/10.1136/ jech-2020-216108).

${ }^{1}$ School of Earth and Environment, University of Canterbury, Christchurch, New Zealand

${ }^{2}$ GeoHealth Laboratory, University of Canterbury, Christchurch, New Zealand ${ }^{3}$ School of Health Sciences, University of Canterbury, Christchurch, New Zealand ${ }^{4}$ Department of Environmental Science, Aarhus University, Roskilde, Denmark

${ }^{5}$ New Zealand Ministry of Health, Wellington, New Zealand
\end{abstract}

\section{Correspondence to}

Dr Malcolm Campbell, Earth and Environment, University of Canterbury, Christchurch 8020, New Zealand;

Malcolm.Campbell@Canterbury. ac.nz

Received 23 November 2020 Revised 24 January 2021 Accepted 31 January 2021 Published Online First 16 March 2021

\begin{abstract}
Background The COVID-19 pandemic has asked unprecedented questions of governments around the world. Policy responses have disrupted usual patterns of movement in society, locally and globally, with resultant impacts on national economies and human well-being. These interventions have primarily centred on enforcing lockdowns and introducing social distancing recommendations, leading to questions of trust and competency around the role of institutions and the administrative apparatus of state. This study demonstrates the unequal societal impacts in population movement during a national 'lockdown'.

Methods We use nationwide mobile phone movement data to quantify the effect of an enforced lockdown on population mobility by neighbourhood deprivation using an ecological study design. We then derive a mobility index using anonymised aggregated population counts for each neighbourhood (2253 Census Statistical Areas; mean population $n=2086$ ) of national hourly mobile phone location data (7.45 million records, 1 March 2020-20 July 2020) for New Zealand (NZ).

Results Curtailing movement has highlighted and exacerbated underlying social and spatial inequalities. Our analysis reveals the unequal movements during 'lockdown' by neighbourhood socioeconomic status in NZ.

Conclusion In understanding inequalities in neighbourhood movements, we are contributing critical new evidence to the policy debate about the impact(s) and efficacy of national, regional or local lockdowns which have sparked such controversy.
\end{abstract}

\section{INTRODUCTION}

Pandemics adversely affect disadvantaged populations and amplify existing social gradients in health where individuals at the top of society maintain better health than those below them. ${ }^{1-3}$ The harmful effects of inequality and inequity have been shown to result in many negative health outcomes. ${ }^{4}$ The COVID-19 pandemic has exposed and widened such entrenched inequities, ${ }^{5}$ that are unjust and avoidable. $^{67}$ For instance, COVID-19 mortality rates in the most deprived areas of the UK are more than double those seen in the least deprived areas. ${ }^{8}$ Pūras et al $l^{9}$ have argued that all populations have the right to equitable healthcare and services, however, during the COVID-19 pandemic, those with sufficient means can self-isolate, buffered often by their income, while those without cannot and are therefore at higher risk of infection and subsequent mortality. ${ }^{1}$ This study aims to use nationwide mobile phone movement data on neighbourhoods to quantify the effect of an enforced lockdown on population mobility by neighbourhood deprivation.

\section{METHODS: MEASURING NATIONAL MOBILITY}

Responding to the appeal from Oliver et al, ${ }^{10}$ we obtained anonymised aggregated population counts for each neighbourhood (2253 Census Statistical Areas; mean population $\mathrm{n}=2086)$ from national hourly mobile phone location data $(7.45$ million records, 1 March 2020-20 July 2020) for New Zealand (NZ), from DataVentures, an agency of the NZ government. The mobile phone data has been postprocessed by the provider to impute the hourly population of every SA2 area for NZ, to account for known biases, similar to the methodology of the NZ Census.

We then created a mobility index (figure 1) to analyse population mobility through NZ's four COVID-19 alert levels, see online supplemental material for details of the alert levels, (which are regularly updated). The data was then stratified into quintiles of neighbourhood deprivation (for the variables contained in the index see online supplemental table S1), using the NZ index of Deprivation 2018, (NZDep2018) ${ }^{11}$ (Q1=least deprived areas) as a proxy of socioeconomic position for each neighbourhood.

The daily mobility index (MI) for a single area is calculated as the average daily value of the increase in hourly population count, compared with the daily minimum population count, per (SA2) area (Eq. 1).

$$
M I_{k}=\frac{1}{n} \sum_{i=1}^{n}\left(\frac{\operatorname{Pop}_{k i}-\min \left(\operatorname{Pop}_{k}\right)}{\min \left(\operatorname{Pop}_{k}\right)}\right)
$$

Where $P_{o p} p_{k i}$ is the population per area $(k)$ per hour $(i), \min \left(\operatorname{Pop}_{k}\right)$ is the minimum daily population per area and $n$ is the number of hours in a day. A daily mobility index of zero corresponds to the baseline or the lowest daily minimum per quintile. For example, if 2000 is the lowest daily minimum count of in an area, and 2200 are counted in a different hourly period, the mobility index for this period would be $10 \%$. Another way of expressing this is that a daily mobility index of $10 \%$ corresponds to $10 \%$ more people than the daily minimum count. In areas with an existing population, the daily mobility index cannot be smaller than zero. 


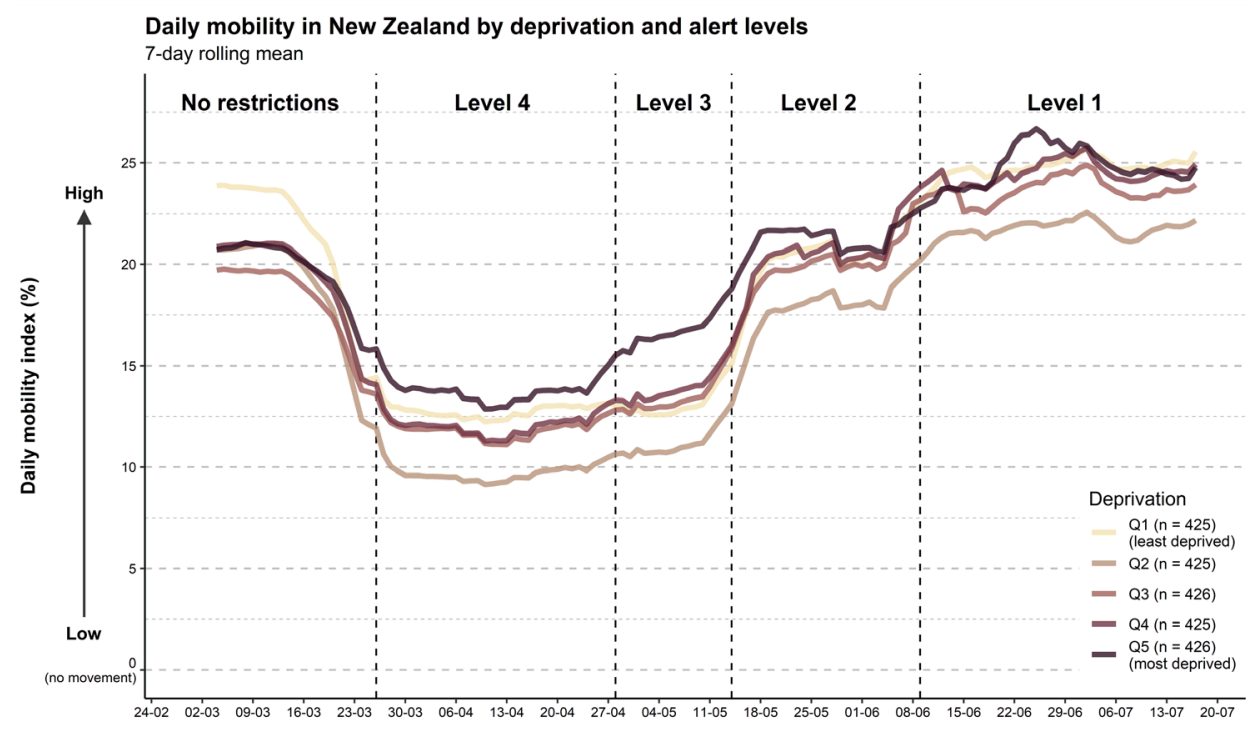

Figure 1 Daily mobility over time by neighbourhood deprivation (New Zealand Deprivation Index 2018 quintile) and national COVID-19 alert level.

Calculated mobility indices of individual areas are then averaged by deprivation quintile for the whole country. To identify trends in mobility, we have also smoothed the data per deprivation quintile into a 7-day rolling mean of the daily mobility index.

\section{RESULTS}

Prior to the implementation of a national lockdown, under no movement restrictions, the highest population mobility was in the least deprived quintile areas (Q1) while the lowest mobility was in Q3, however, these differences are not significant (online supplemental table S3). Figure 1 demonstrates the effectiveness of level 4 restrictions, the most severe movement restrictions, in reducing population mobility. However, the magnitude of this reduction was not uniformly observed with the social stratification evident and statistically significant (online supplemental table S3). The most notable reduction in mobility was in Q2 areas (the relatively less deprived), with much lower movement than all other deprivation quintiles as restrictions began and throughout all alert levels. Additionally, while the least deprived areas (Q1) experienced the highest movement under no restrictions, the most deprived areas (Q5) were the most mobile immediately after level 4 restrictions were introduced. The unequal social impacts of 'lockdown' writ large.

As restrictions began to ease during Level 2, mobility in the less deprived quintile areas (Q1 and Q2) remained lower than prelockdown, whereas the more deprived areas (Q3, Q4 and Q5) increased beyond that of pre-lockdown (figure 1). An unequal recovery from 'lockdown'. Overall, population mobility decreased with the implementation of level 4, then rose steadily with easing restrictions (see online supplemental figure S1). There are indications of increased movement around NZ post-lockdown, with increased domestic travel. Figure 1 also demonstrates the speed at which populations return to 'normal' behaviours following restricted mobility and the anticipation of change in alert levels, particularly when restrictions eased, with increases in mobility near the end of each level. For a comparison to pre-COVID-19 (see online supplemental figure S2) for the same period in 2019, where there is little seasonal effect and the mobility index is highest in the least deprived areas (Q1).

\section{DISCUSSION}

$\mathrm{NZ}$ is an instructive example as an Organisation for Economic Co-operation and Development (OECD) country, comparable to many western democracies. Our nationwide analysis offers unique insights into population mobility during nationwide lockdown and the subsequent easing of restrictions by socioeconomic status. We have observed clear variations in mobility by socioeconomic status. Interestingly, all populations demonstrated cautious self-regulating behaviours, anticipating level changes, prior to level 4 , and then relaxing ahead of restrictions easing. This could be in response to concerns of community transmission, perceived changes in risk and apathy towards the end of the period. The daily patterns naturally are layered by local weather conditions (with warm or wet days impacting mobility), occurrence of national holidays and weekday/weekend variations.

There are likely various motivations for differential mobility between deprivation levels. Deprived areas disproportionately house the lower paid, who could be essential workers, (ie, supermarket or public transport employees) who are permitted to be mobile under lockdown, which explains enhanced movement in Q5 areas. An alternative explanation is that Q5 areas have the highest proportion (29\%) of supermarkets per quintile across the country (online supplemental table S2), compared with only $11 \%$ being located in Q1 areas. This would be a likely motivation to increase mobility into Q5 areas.

There are also other factors at play in deprived neighbourhoods, such as a lack of financial resilience to withstand sustained lockdown that will encourage greater mobility. ${ }^{5}$ Conversely, the less deprived (Q1-Q2) neighbourhoods are more likely to be populated with higher paid 'professionals' who may be able to work from home or shield themselves with pre-existing capital, hence reducing movement. We favour the explanation that it is occupation differences that exacerbate daily movement during the lockdown.

There are caveats to our analysis. Population or demographic factors, such as age, may be masking the relationships we have observed. When using aggregated geographical data, an important consideration is not to conflate people with place(s). We have been able to model and visualise aggregated population movements by place, not the underlying individual movements, 
in social science this is called the ecological fallacy, ${ }^{10}$ we need to be careful to recognise this difference in scale. Moreover, using our methodology, mobility will be recorded differently between urban and rural areas. Rural areas tend to be larger, meaning rural populations can move larger distances before mobility is detected, and mobile phone reception may be an issue. Future work could control for age, sex, ethnicity and occupation of the census areas. Further, the precise nature of daily population fluctuations from commuting and coherence with the usually resident population from the NZ Census 2018, could be examined.

We have unpacked how neighbourhood deprivation leads to difference in experiencing the COVID-19 lockdown restrictions. These findings may help to begin to inform the differential COVID-19 infection, mental health impacts and the post-COVID-19 recovery between the most and least affluent areas. The consideration of inequality in mobility is vital not just for COVID-19, but also for any future pandemic and the policy response associated with it. This 'natural experiment' is instructive in proving a one-size policy does not fit all neighbourhoods.

This study also demonstrates that movement data is invaluable in determining the efficacy of the policies that have been (or may still have to be) implemented as part of the pandemic response. In this case, we raise the issue of the socioeconomic determinants to mobility that must be considered in future pandemic policy responses.

\section{What is already known on this subject}

- The existence of societal gradients in health is well established.

- There is ample evidence on the existence of social and geographical inequality in non-communicable and infectious diseases.

\section{What this study adds}

- The emergence of COVID-19 provided a 'natural experiment' in the application of national policy to illuminate the differing neighbourhood movements by socioeconomic position.

- This study uses comprehensive nationwide data to highlight the unequal impacts of national policy on the movements by neighbourhood socioeconomic position for a whole country. We demonstrate the importance of understanding underlying social fractures in the application of policy.

Twitter Malcolm Campbell @CampbellMH, Lukas Marek @_lukasmarek_. Matthew Hobbs @hobbs_PA, Clive E Sabel @Clive_Sabel and Simon Kingham @ SimonKingham

Acknowledgements The authors would like to thank Statistics New Zealand and Data Ventures for the provision of aggregated mobile phone data.
Contributors MC: conception of idea, data analysis, writing and editing of manuscript; LM: conception of idea, data analysis, writing and editing of manuscript. JW: conception of idea, writing and editing of manuscript. $\mathrm{MH}$ : conception of idea, writing and editing of manuscript. CES: writing and editing of manuscript. JM: conception of idea, writing and editing of manuscript. SK: writing and editing of manuscript.

Funding The GeoHealth Laboratory is funded by the New Zealand Ministry of Health. BERTHA is funded by the Novo Nordisk Foundation (grant NNF170C0027864)

Competing interests None declared.

Patient consent for publication Not required.

Provenance and peer review Not commissioned; externally peer reviewed.

Supplemental material This content has been supplied by the author(s). It has not been vetted by BMJ Publishing Group Limited (BMJ) and may not have been peer-reviewed. Any opinions or recommendations discussed are solely those of the author(s) and are not endorsed by BMJ. BMJ disclaims all liability and responsibility arising from any reliance placed on the content. Where the content includes any translated material, BMJ does not warrant the accuracy and reliability of the translations (including but not limited to local regulations, clinical guidelines, terminology, drug names and drug dosages), and is not responsible for any error and/or omissions arising from translation and adaptation or otherwise.

Open access This is an open access article distributed in accordance with the Creative Commons Attribution Non Commercial (CC BY-NC 4.0) license, which permits others to distribute, remix, adapt, build upon this work non-commercially, and license their derivative works on different terms, provided the original work is properly cited, appropriate credit is given, any changes made indicated, and the use is non-commercial. See: http://creativecommons.org/licenses/by-nc/4.0/.

\section{ORCID iDs}

Malcolm Campbell http://orcid.org/0000-0001-7975-4662

Lukas Marek http://orcid.org/0000-0001-5473-8930

Jesse Wiki http://orcid.org/0000-0002-1060-687X

Matthew Hobbs http://orcid.org/0000-0001-8398-7485

Clive E Sabel http://orcid.org/0000-0001-9180-4861

Simon Kingham http://orcid.org/0000-0002-2869-3756

\section{REFERENCES}

1 Bambra C, Riordan R, Ford J, et al. The COVID-19 pandemic and health inequalities. J Epidemiol Community Health 2020;74:964-8.

2 Marmot M, Allen J. COVID-19: exposing and amplifying inequalities. J Epidemiol Community Health 2020;74:681-2

3 McCartney G, Leyland A, Walsh D, et al. Scaling COVID-19 against inequalities: should the policy response consistently match the mortality challenge? J Epidemiol Community Health 2020. doi:10.1136/jech-2020-214373. [Epub ahead of print: 03 Nov 2020]

4 Marmot M. Health equity in England: the Marmot review 10 years on. BMJ 2020:368:m693

5 Dorn Avan, Cooney RE, Sabin ML. COVID-19 exacerbating inequalities in the US. Lancet 2020:395:1243-4.

6 Chowkwanyun M, Reed AL. Racial health disparities and Covid-19 - caution and context. N Engl I Med Overseas Ed 2020:383:201-3.

7 Hobbs M, Ahuriri-Driscoll A, Marek L, et al. Reducing health inequity for Māori people in New Zealand. Lancet 2019:394:1613-4.

8 Public Health England. COVID-19: review of disparities in risks and outcomes. London, 2020.

9 Pūras D, de Mesquita JB, Cabal L, et al. The right to health must guide responses to COVID-19. Lancet 2020;395:1888-90.

10 Oliver N, Lepri B, Sterly H, et al. Mobile phone data for informing public health actions across the COVID-19 pandemic life cycle. Sci Adv 2020;6:eabc0764.

11 Atkinson J, Salmond C, Crampton P. NZDep2018 index of deprivation. Wellington: University of Otago, 2019. 